Nature Climate Change

February 2016, Volume 6 Issue 2 Pages 145-153

http://dx.doi.org/10.1038/NCLIMATE2872

http://archimer.ifremer.fr/doc/00310/42106/

(c) 2016 Macmillan Publishers Limited

\title{
Fifteen years of ocean observations with the global Argo array
}

\author{
Riser Stephen C. ${ }^{1}$, Freeland Howard J. ${ }^{2,}{ }^{*}$, Roemmich Dean ${ }^{3}$, Wijffels Susan ${ }^{4}$, Troisi Ariel ${ }^{5}$, \\ Belbeoch Mathieu ${ }^{6}$, Gilbert Denis ${ }^{7}$, Xu Jianping ${ }^{8}$, Pouliquen Sylvie ${ }^{9}$, Ann Thresher ${ }^{4}$, \\ Le Traon Pierre-Yves ${ }^{10,}{ }^{11}$, Maze Guillaume ${ }^{9}$, Klein Birgit ${ }^{12}$, Ravichandran M. ${ }^{13}$, Grant Fiona ${ }^{14}$, \\ Poulain Pierre-Marie ${ }^{15}$, Suga Toshio ${ }^{16,17}$, Lim Byunghwan ${ }^{18}$, Sterl Andreas ${ }^{19}$, Sutton Philip ${ }^{20}$, \\ Mork Kjell-Arne ${ }^{21}$, Joaquin Velez-Belch Pedro ${ }^{22}$, Ansorge Isabelle ${ }^{23}$, King Brian ${ }^{24}$, Turton Jon ${ }^{25}$, \\ Baringer Molly ${ }^{26}$, Jayne Steven R. ${ }^{27}$
}

${ }^{1}$ Univ Washington, Dept Oceanog, Seattle, WA 98195 USA.

${ }^{2}$ Inst Ocean Sci, Fisheries \& Oceans Canada, North Saanich, BC V8L 4B2, Canada.

${ }^{3}$ Scripps Inst Oceanog, 9500 Gilman Dr,0230, La Jolla, CA 92093 USA.

${ }^{4}$ CSIRO, Ctr Australian Weather \& Climate Res, Hobart, Tas 7004, Australia.

${ }^{5}$ Serv Hidrog Naval, A Montes Oca 2124,Buenos Aires C1270 ABV, Buenos Aires, DF, Argentina.

6 Joint Commiss Oceanog \& Marine Meteorol Operat JC, BP 70, F-29280 Plouzane, France.

${ }^{7}$ Inst Maurice Lamontagne, Fisheries \& Oceans Canada, Mont Joli, PQ G5H 3Z4, Canada.

${ }^{8}$ SOA, Inst Oceanog 2, 36 Baochubei Rd, Hangzhou 310012, Zhejiang, Peoples R China.

9 IFREMER, BP 70, Plouzane, France.

${ }^{10}$ IFREMER, 8-10 Rue Hermes Parc Technol Canal, F-31520 Ramonville St Agne, France.

${ }^{11}$ Mercator Ocean, 8-10 Rue Hermes Parc Technol Canal, F-31520 Ramonville St Agne, France.

${ }^{12}$ Bundesamt Seeschiffahrt \& Hydrog, Bernhard Nocht Str 78, D-20359 Hamburg, Germany.

${ }^{13}$ Indian Natl Ctr Ocean Informat Serv, Hyderabad 500090, Andhra Pradesh, India.

${ }^{14}$ Inst Marine, Int Programmes, Wilton Pk House,Wilton PI, Dublin 2, Ireland.

${ }^{15}$ OGS, 42-C Sgonico, I-20359 Trieste, Italy.

16 JAMSTEC, Aoba Ku, Aramaki Aza Aoba 6-3, Sendai, Miyagi 9808578, Japan.

17 Tohoku Univ, Aoba Ku, Aramaki Aza Aoba 6-3, Sendai, Miyagi 9808578, Japan.

${ }^{18}$ Natl Inst Meteorol Sci KMA, 33 Seohobuk Ro, Seogwipo Si 63568, Jeju Do, South Korea.

${ }^{19}$ KNMI, POB 201, NL-3730 AE De Bilt, Netherlands.

${ }^{20}$ Natl Inst Water \& Atmospher Reseach, 301 Evans Bay Parade,Greta Point, Wellington 6021, New

Zealand.

${ }^{21}$ Marine Res Inst, POB 1870 Nordes, N-5817 Bergen, Norway.

${ }^{22}$ Inst Espanol Oceanog, Via Espaldon,Darsena Pesquera,Parcela 8, Santa Cruz de Tenerife 38180, Spain.

${ }_{23}$ Univ Cape Town, Inst Marine Res, Dept Oceanog, ZA-7701 Rondebosch, South Africa.

${ }^{24}$ Natl Oceanog Ctr, Southampton S014 3ZH, Hants, England.

${ }^{25}$ Met Off, FitzRoy Rd, Exeter EX1 3PB, Devon, England.

${ }^{26}$ NOAA, Atlantic Oceanog \& Meteorol Lab, 4301 Rickenbacker Causeway, Miami, FL 33149 USA.

${ }^{27}$ Woods Hole Oceanog Inst, Woods Hole, MA 02543 USA.

* Corresponding author : Howard Freland, email address : Howard.Freeland@dfo-mpo.gc.ca 


\begin{abstract}
:
More than $90 \%$ of the heat energy accumulation in the climate system between 1971 and the present has been in the ocean. Thus, the ocean plays a crucial role in determining the climate of the planet. Observing the oceans is problematic even under the most favourable of conditions. Historically, shipboard ocean sampling has left vast expanses, particularly in the Southern Ocean, unobserved for long periods of time. Within the past 15 years, with the advent of the global Argo array of pro ling oats, it has become possible to sample the upper $2,000 \mathrm{~m}$ of the ocean globally and uniformly in space and time. The primary goal of Argo is to create a systematic global network of pro ling oats that can be integrated with other elements of the Global Ocean Observing System. The network provides freely available temperature and salinity data from the upper 2,000 $\mathrm{m}$ of the ocean with global coverage. The data are available within 24 hours of collection for use in a broad range of applications that focus on examining climate-relevant variability on seasonal to decadal timescales, multidecadal climate change, improved initialization of coupled ocean-atmosphere climate models and constraining ocean analysis and forecasting systems.
\end{abstract}




\section{Introduction}

33 In the late 1990s it was recognized that little progress would be made monitoring the changing climate of the

34 Earth without systematic global observations. A small group of oceanographers proposed that some readily35 available technology could be adapted and, with sufficient international cooperation, be used to create a global array of floats that could supply real-time global views of the ocean. Thus was born the Argo program. This article reviews the progress made in the first 15 years of Argo and attempts to provide an outline of how the program is likely to change over the next decade.

\section{History and present status}

The Argo program ${ }^{1}$ is a major component of the Global Ocean Observing System ${ }^{2}$ and strives to monitor the evolving temperature and salinity fields of the upper ocean The profiling floats used in Argo are 2-meter long, freely drifting robotic devices that adjust their depth in the ocean by changing their buoyancy. In the context of Argo, the majority of these instruments are programmed to drift at a nominal depth of 1000 meters (known as the parking depth). A typical duty cycle of an Argo float is shown in Figure 1. Floats are launched at the sea surface and dive to a so-called parking depth of 1000 meters. After a 9-day interval at the parking depth, the floats descend to 2000 meters, then rise over a period of roughly 6 hours to the sea surface, sampling ocean properties such as temperature and salinity during their ascent. At the surface the data are transmitted to land stations via satellite; the floats then descend back to the parking depth to begin another cycle. A typical float will repeat this 10-day cycle in excess of 200 times over the course of five years or more. Over 10,000 floats have been deployed by the nations participating in the program since the beginning of Argo, with almost 3900 floats presently operating over the world-ocean. A defining aspect of Argo is that all data are reported in near realtime to meteorological forecasting centers and to the two Argo Global Data Assembly Centers (GDACs, localized in the USA and France), from which the accumulated data are made freely available without 55 limitation.

Argo float deployments began in 1999. The original program plan called for an array with global coverage of about 3000 floats by the year 2007, a goal that was achieved in November of that year. The resulting improvement in sampling the ocean achieved by Argo compared with the previous century of measurements is dramatic (Fig. 2). Historically, oceanographic sampling has had a bias towards areas that are more easily sampled, so the Northern Hemisphere and coastal regions are over-represented. Though Argo floats cannot sample in shallow coastal waters, the program has helped eliminate these spatial biases. Argo has also eliminated a major seasonal bias in sampling, particularly in the polar oceans; presently Argo delivers more winter profiles in the Southern Ocean in one year than the total of all winter data collected during the 100 years 
64 prior to Argo, and the majority of the temperature and salinity observations from the Southern Ocean (defined 65 here as the ocean south of $30^{\circ} \mathrm{S}$ ) in the global database now originate from Argo.

66 In Chapter 3 of its Fifth Assessment Report (hereinafter AR5) ${ }^{5}$, the Intergovernmental Panel on Climate Change 67 (IPCC) Working Group 1 included an Appendix on the Availability of Observations for Assessment of Change 68 in the Oceans showing the distribution of temperature and salinity profile data from the 1950-1955 to the 2005692010 pentads; these results indicate the general lack of observations prior to 2000, as well the Northern 70 Hemispheric bias within the pre-Argo observing system. Although not shown in AR5, there is also a known 71 seasonal bias, with the local winter season being generally under-represented in the pre-Argo observing system. 72 It is apparent from this report that the recent expansion of the ocean observing system clearly sets AR5 apart 73 from its predecessor ${ }^{6}$, with most of this change ascribed to the existence of the Argo array. Some issues remain 74 that are being addressed. Since Argo floats must reach the sea surface to transmit their data, Argo could not originally target ice-covered parts of the oceans; now floats are successfully operating in the Antarctic seasonal ice zone ${ }^{7,8}$. Within the temperate oceans coverage is not homogeneous, but there are efforts to increase coverage in under-sampled regions such as near western boundary currents.

While the volume of Argo data easily overwhelms traditional sources, the quantity is of value only if the quality of the data is high. The original Argo target called for temperature and salinity accuracies of $0.005^{\circ} \mathrm{C}$ and 0.01 salinity units, with a pressure accuracy of 2.5 decibars (equivalent to a depth error of about 2.5 meters). Experience has shown that about $80 \%$ of the raw profile data transmitted from the floats meet these standards, with little or no correction required. The other $20 \%$ of the data are corrected using delayed-mode quality control procedures developed over the past decade ${ }^{9,10,11}$, with nearly all of these profiles eventually meeting the accuracy goals. Agencies developing operational forecast systems require data in a timely fashion. Currently, about $90 \%$ of Argo profiles are distributed electronically within 24 hours of acquisition.

\section{Recent Results and Findings}

Perhaps the single most powerful metric of the value of Argo is the widespread use of the data produced by the program: since the beginning of Argo in the late 1990s, more than 2100 papers in the refereed science literature have used Argo observations, attesting to the array's value in expanding our understanding of the oceans and climate. The key ocean state variables, temperature and salinity varying with pressure and velocity were measured (or for velocity, mostly inferred) in the world ocean for at least a century prior to the initial deployment of the Argo array. During the 1980s and 1990s the World Ocean Circulation Experiment (WOCE) produced about 8000 high quality ship-based profiles along a number of tracks across the ocean that provide a 
unobserved in WOCE due to the limited number of lines that could be occupied, particularly in the Southern Ocean. In this context, the high sampling density and repeat frequency of the Argo observations, in conjunction with their overall quality, have led to important new insights into the nature of the general circulation of the ocean.

While compilations of thousands of ship-based observations of ocean temperature and salinity have been averaged and made available as digital atlases since at least the $1980 \mathrm{~s}^{12}$, they suffer from the sampling biases previously noted. With data collected by Argo now becoming the overwhelming majority of observations in the global database, there is an unprecedented opportunity to map the detailed structure of the global ocean temperature and salinity fields, at both surface and subsurface levels, and both globally and locally ${ }^{13}$. These estimates allow the development of climate indicators such as the recent changes in ocean heat content and thermosteric sea level. The global velocity dataset produced by Argo floats ${ }^{14}$ is beginning to be used in systematic (and previously impossible) studies ${ }^{15,16}$ to quantify directly the subsurface interior flow fields. The Argo data have also been used to improve our view of the complex structure of oceanic variability at spatial scales smaller than the climate scale. A number of studies have examined properties of mesoscale eddies using Argo profiles ${ }^{17,18}$, and it has been possible to describe the spatial variability in the internal gravity wave field ${ }^{19}$, even though such applications were not envisioned when Argo began.

Argo complements the other elements of the global ocean observing system, in particular satellite altimetry. The combination of in situ Argo data with sea surface height anomalies derived from satellites allows the construction of time series of the dynamical state of the ocean circulation (such as the North Atlantic meridional overturning circulation ${ }^{20}$ ) and high-resolution three-dimensional temperature fields ${ }^{21}$. Techniques have been presented $^{22,23}$ whereby geostrophic computations relative to 1000 decibars can be merged with a combination of satellite altimetry observations and trajectory data to yield estimates of the absolute circulation fields, in wellsampled areas. Argo data are now systematically used together with altimeter data for ocean analysis and forecasting. Most climate models assimilate the subsurface temperature observations from Argo, leading to improved forecasts of intraseasonal waves in the atmosphere, monsoon activity, and ocean-atmosphere interactions such as the El Nino Southern Oscillation (ENSO) ${ }^{224}$.

Given that they provide a comprehensive baseline of today's ocean state, the Argo observations have been especially useful in examining ocean changes on time scales of decades and longer. A stunning example ${ }^{25}$ has used contemporary Argo observations in conjunction with data from the HMS Challenger expedition, carried out in the second half of the 19th Century. The study reveals a warming of the ocean over the past 135 years of nearly $0.6^{\circ} \mathrm{C}$ near the sea surface, tapering to near zero at depths near $1000 \mathrm{~m}$ (Fig. 3). Over the upper $900 \mathrm{~m}$ of much of the ocean there is an average increase in temperature of over $0.3^{\circ} \mathrm{C}$ over the 135 -year study interval. This work, further supported by analogous results in climate models ${ }^{26}$, underscores the changing nature of ocean 
129 properties and the need to sustain global observing systems over long periods and, further, that recent changes in 130 ocean temperature likely predate the sparse global-scale ocean datasets of the past half century.

131 A more detailed comparison of Argo profiles available in the time frame 2004-2008 with data in the ship-based 132 data archive (containing data collected through $2001^{27}$ ) shows global-scale changes in both temperature and 133 salinity ${ }^{28}$ in the upper kilometer of the world ocean in recent decades. The comparison suggests that most 134 regions of the world ocean are warmer in the near surface-layer than in previous decades, by over $1^{\circ} \mathrm{C}$ in some 135 places. A few areas, such as the eastern Pacific from Chile to Alaska, have cooled by as much as $1^{\circ} \mathrm{C}$, yet 136 overall the upper ocean globally has warmed by nearly $0.2^{\circ} \mathrm{C}$ since the mid-20th century. A recent update of 137 this work ${ }^{29}$ shows the warming continues to be observed through at least 2013.

138 Prior to the beginning of Argo, ocean salinity was much more poorly sampled than temperature. The highest 139 quality salinity measurements that existed prior to Argo were made during WOCE in the 1980s and 1990s, with 140 periodic reoccupation of some of these sections continuing. With the advent of Argo, it is possible to examine 141 the global variability of salinity above $2000 \mathrm{~m}$ with some confidence for the first time. As with temperature, a 142 comparison of Argo results with earlier data ${ }^{30}$ clearly shows decadal-scale changes in ocean salinity. A related 143 study that compared the Argo results with the data in the older archives ${ }^{31}$ identified a pattern of change in upper 144 ocean salinity in each of the major ocean basins. This change appears consistent with a general warming of the 145 surface layers, causing a poleward migration of wintertime density outcrops. Because there are pole-to-equator 146 temperature and salinity gradients at the sea surface, the surface waters at any latitude are subducted below those 147 at lower latitudes as they circulate towards the equator, with a poleward migration of density yielding a 148 generally lower salinity at higher latitudes. At mid-latitudes, surface warming is accompanied by increased 149 evaporation from the sea surface, thus increasing the salinity of the near-surface waters. When compared, 150 surface and basin-scale contrasts in salinity are found consistently to be strengthening ${ }^{29,30,31}$. This amplification, 151 with fresh areas getting fresher and salty areas becoming more saline, is consistent with an overall net increase 152 of water vapor transport through the atmosphere, and is also seen to occur in climate models that very closely 153 follow Clausius-Clapeyron thermodynamics ${ }^{32}$.

154 On more regional scales, Argo data have been used to examine the variable nature of deep ocean ventilation, 155 which is important in sequestering heat and gases into the vast subsurface layers of the ocean. This process 156 occurs at a few high latitude sites in the North Atlantic and the Antarctic, and the resulting circulation induced 157 by this sinking has long been thought to have an important influence on century-scale climate variability ${ }^{33}$. The 158 Labrador/Irminger Sea region in the high-latitude N. Atlantic has been extensively examined by Argo in the past 159 decade, with the observations (combined with ship-based datasets and atmospheric heat flux estimates) showing 160 the high sensitivity of the strength of deep convection to year-to-year variations in the wintertime atmospheric 161 conditions $^{34}$. That work has recently been brought up to date ${ }^{35}$ and the result is a spectacular demonstration (Fig. 
162 4) of the power of Argo to show variability of deep convection in the Labrador Sea and in 2014 the deepest 163 convection observed since 2008.

164 More detailed, regional views of the effects of changing near-surface temperature and salinity, from the central 165 North Pacific, using Argo profiles together with older, ship-based data in the region, have shown a general 166 decrease in upper ocean salinity in the tropics and subtropics, caused by a freshening of the source waters for the 167 upper ocean in the region, essentially water in the surface mixed layer at higher latitudes in winter ${ }^{36,37}$. This 168 freshening can be attributed to a combination of factors, including increased local precipitation or the poleward 169 migration of the source region due to regional warming. The data availability in this region (including Argo and 170 other datasets) is rich enough to allow an actual heat budget to be constructed, suggesting that precipitation and 171 wintertime entrainment of subsurface water into the mixed layer are the most important factors in determining 172 the surface density over time, and hence also the surface salinity. It appears likely that these factors will change 173 in response to a changing climate state. Elsewhere in the North Pacific, temperature and salinity properties 174 along a track originating off Vancouver Island have been regularly surveyed by research vessels since the 1950s, 175 and in the past decade these surveys have been augmented by Argo observations. The combination of the older 176 data and $\operatorname{Argo}^{38}$ also show that subpolar surface waters are warming and freshening, resulting in a lower surface 177 density (and higher near-surface stratification), thus limiting the direct influence of the atmosphere on the 178 subsurface ocean.

179 As noted, a number of observation-based studies have concluded that the upper layers of the global ocean have 180 warmed in recent decades, or even over a longer term. Yet it is the change in heat storage by the ocean 181 (essentially the vertical integral of temperature change) that is likely to be directly related to the planetary 182 radiation imbalance ${ }^{39,40}$. It appears that the observed increase in ocean heat content in the upper $700 \mathrm{~m}$ over the 183 past 40 years, inferred from Argo and hydrographic observations, is the dominant term in the global inventory of 184 heating changes, with over $90 \%$ of the excess heat in the climate system being stored in the oceans ${ }^{41}$. Without 185 Argo, it is unlikely that such a conclusion could have been drawn. The data have also allowed temporal spatial 186 variations in ocean heat content to be discerned ${ }^{42}$, suggesting that most of the increase in heat content in the past 187 decade has occurred in the Southern Ocean (which was poorly sampled prior to Argo); it has also been noted ${ }^{43}$ 188 that ENSO variability in the tropical Pacific has for now somewhat obscured the global increase in sea surface 189 temperature. Some of these ideas have been tested using Argo data alone (Fig. $5^{29}$ ), by examining the change in 190 heat content of the upper $2000 \mathrm{~m}$ of the ocean in three latitudinal bands from 2006 to the present time; during 191 the Argo era it can be seen that the ocean is warming, mostly south of $20^{\circ} \mathrm{S}$. In Figure 5 the Argo-only plots 192 (shown as an inset) are only for the years 2006-2014, inclusive, the period when global coverage from Argo 193 exists. So these short plots are overlaid on a plot of heat content estimates 0-2000 m for the period 1955-2010 ${ }^{44}$. 194 The Argo estimates show a very similar trend. This is a crucial result in making an assessment of the ocean's 
role in climate change, one that would have likely been impossible prior to Argo. Indeed, a recent detailed and systematic analysis of the change in ocean heat content and our ability to observe $i^{45}$ concludes that estimates of the upper ocean heat content based on data collected prior to Argo systematically underestimate the amount of heat content change, mostly due to under-sampling of the Southern Hemisphere ocean; with the advent of a significant amount of Argo data becoming available around 2004, the estimates are greatly improved and show much improved agreement with climate models.

\section{Future prospects}

When Argo began in the late 1990s, it was by no means clear that the project would be successful in deploying and sustaining an array of 3000 floats over the global ocean, as the required technology was in its infancy and the degree of international cooperation required was unprecedented in the oceanographic community. Now, in the second decade of the 21st century, the float technology is well proven, and over 30 countries are contributing resources to Argo, making it sensible to contemplate expansions of its mission. The Argo Steering Team (hereinafter AST) has provided a roadmap ${ }^{46}$ for how the project might evolve and expand in the next decade, and some of this proposed development is now underway via test deployments or regional pilot arrays. One project is to support an increase in the spatial sampling resolution in special parts of the world ocean where the ocean is especially turbulent (challenging the array's signal resolving power) and the interaction of the ocean and the atmosphere and the resulting climate impacts are especially strong. Improved technology also allows us to expand Argo into previously unsampled regions such as marginal seas and the seasonal ice-zone, implying that the array is more truly global in its coverage than its original design.

Intense western boundary currents such as the Gulf Stream and Kuroshio are some of the most striking features of the ocean circulation, serving to transport heat poleward as they carry warm tropical and subtropical waters to higher latitudes. A sizeable portion of this heat is exchanged with the atmosphere along the path of the flow, especially after these currents separate from the boundary and enter the interior of the ocean, altering the tracks of storms and perhaps ameliorating continental climates ${ }^{47}$. When Argo data are used to map monthly and seasonal evolution of the large-scale ocean structures in these regions, the errors are relatively high compared to other regions due to the presence of the vigorous ocean turbulence associated with these boundary current regimes and the lack of spatial resolution of the Argo array. This limits the ability of Argo to achieve one of its main goals, which is to observe the slow evolution of the large-scale ocean structure in these important regions. The AST has suggested that extra float resources should be committed to the study of these regions, and some of the nations that contribute to the array have responded to this call. In the western North Pacific, for example, the boundary domain adjacent to China, South Korea, and Japan is already sampled at a spatial density nearly three times the standard Argo protocol. In the western North Atlantic, between Cape Hatteras and the mid- 
Atlantic Ridge, the sampling is similarly dense. The ability of the program to enhance sampling in all western boundary current regions is unclear, but these pilot activities will help demonstrate the gains made and thus guide the future sampling recommendations.

A similar increase in sampling density is called for in near-Equatorial regions, where strong air-sea coupling can produce global-scale atmospheric anomalies. The tropical Pacific, for example, is the gestation site of the ENSO phenomenon, an irregular seesaw of oceanic warming and cooling that can, via strong coupled amplification, drive global climate variability and cause economic impacts at sites far removed from the lowlatitude Pacific. The Indian Ocean Dipole (IOD) is an analogous phenomenon that impacts Indian Ocean rim nations ${ }^{46}$. The surface temperature and salinity associated with these phenomena can be monitored via satellites, but Argo is now the main source of information on their deeper, subsurface expressions. Argo data are used in model forecasts for ENSO and the IOD, and, along with the existing tropical moored arrays, are central to providing and improving predictions of the onset and strength of these scientifically interesting yet socially disruptive events.

Additionally, the AST has encouraged the deployment of floats in marginal seas, environments that are regionally important to natural resources and trade. During the early stages of Argo it was decided to avoid deployments in such areas, due to the likely premature loss of floats and troublesome political issues. More than a decade later some of these issues remain, yet the scientific success of Argo has encouraged a number of groups to begin Argo-like programs in several of the marginal seas of the world. Within the Euro-Argo European Research Infrastructure Consortium that is coordinating European contributions to Argo, the MedArgo initiative has maintained an array of more than 50 floats in these regions since 2008 and has plans for expansion. This has helped to clarify the details of water mass formation in the Mediterranean and to improve predictions of the basin-scale circulation by assimilating profile data into numerical models of the circulation. Argo-type efforts in the marginal seas of East Asia have yielded new insights into the interplay of the local ocean and the regional climate in these regions and the nature and causes of long-term changes in their properties, and data resulting from deployments now underway in the Gulf of Mexico will likely eventually be useful in improved hurricane prediction.

Argo was originally planned to cover the open ocean equatorward of $60^{\circ}$, thus purposefully avoiding regions seasonally covered in sea ice. A float trapped under sea ice cannot transmit its data, and, for floats that are somehow able to get to the surface in the presence of ice, the danger of being crushed between floes is sizable. In the past decade algorithms have been developed ${ }^{48}$ that greatly increase a float's chances of surviving the winter in the ice zone by inferring the presence of ice from the near-surface temperature structure. Simply stated, if the float determines that ice is present through an on-board analysis of the stratification, then it avoids the surface (thus avoiding the ice), stores its profile and descends for another cycle. In the spring, when the ice 
retreats and the float can reach the surface, all of its winter data can be transmitted, though without tracking information. This concept has worked well ${ }^{7,8}$ with floats in the seasonal ice zone surviving at about the same rate as floats at lower latitudes. Based on this success, the large fraction of the area of the global ocean that exists at high southern latitudes, and the importance of ice-covered regions around the Antarctic in setting the conditions for meridional overturning, the AST has suggested that deployments in such regions should be systematically increased. Several float deployment groups are now staging pilot deployments in these regions.

Beyond deployments in new regions and advances in float software, technological developments have provided new capabilities to profiling floats that allow a larger range of scientific questions to be examined. As originally designed, Argo was intended to be a program to examine the temperature, salinity, and heat content of the world ocean and the climate implications of the variability in these quantities. In the past decade new sensors have come into existence that also allow biogeochemical variables such as dissolved oxygen, nitrate, chlorophyll, and $\mathrm{pH}$ to be measured from Argo-type floats. These sensors are small in both physical size and power consumption and barely affect the duration of the basic float mission, and thus floats equipped with such sensors allow the prospect of examining the impact of physical aspects of the ocean circulation on key biogeochemical processes sensitive to the climate state, such as the biogeochemical cycle of carbon, ocean deoxygenation, and ocean acidification ${ }^{50}$. These floats will also contribute to the improvement of the capabilities of biogeochemical models ${ }^{51}$ and to the extension of surface biogeochemical properties monitored by ocean color satellites to deeper levels of the water column ${ }^{52}$. The AST has endorsed the general idea of taking advantage of these new developments, while at the same time moving cautiously as the Argo data system gains experience in ingesting and disseminating these new data types. While it is expected that the number of biogeochemical Argo floats deployed will increase dramatically in the coming years, pilot projects in a few key oceanic areas where carbon uptake is crucial will be carried out before envisaging the implementation of a biogeochemical float program at the global scale. Several European efforts in this regard are underway in the North Atlantic. Similarly, the mating of the under-ice capabilities and biogeochemical floats has led to plans by the Southern Ocean Carbon and Climate Observations and Models (SOCCOM) group to examine the carbon cycle around the Southern Ocean, a region responsible for roughly $40 \%$ of the global oceanic carbon uptake. ${ }^{53,54}$ In recent years a series of papers ${ }^{55,56,57,58}$ have shown that the deep ocean well below $2000 \mathrm{~m}$ contributes a significant fraction of the total water column increases in heat content and thermosteric sea level rise, especially in (but not confined to) the high southern latitudes. This warming, in many cases present at all depths below $3000 \mathrm{~m}$, has been deduced from an analysis of sparse but repeated high-quality ship-based observations of temperature and salinity conducted since the 1980s. While the capability of making such measurements from

292 ships has existed for several decades, the cost of the vessels carrying out such work is high, often as much as 293 US\$35K per day. Argo floats, on the other hand, are a seemingly more economical way to observe the ocean, 
although the present generation of Argo floats generally samples no deeper than $2000 \mathrm{~m}$. The economy may or may not be illusory depending on the strategy used to deploy floats. If floats are deployed on a ship of opportunity there may be no incremental launch costs, but strategic launches do often require a dedicated vessel. In order to begin to explore the abyssal ocean and to refine present estimates of the warming of the deep sea, the AST, has since 2012, supported efforts to develop floats capable of profiling deeper than $2000 \mathrm{~m}$ (to as deep as $6000 \mathrm{~m}$ ) and to begin deploying these floats increasingly in 2015 and beyond. This is by far the most ambitious, and technically challenging, development in Argo since the initial float deployments took place in the late 1990s. At the present time several prototypes have been tested that use new technologies, such as carbon-epoxy filament wound cylindrical hulls for a $4000 \mathrm{~m}$ prototypes being developed in Europe and Japan, or hulls made from glass spheres, for two $6000 \mathrm{~m}$ versions being developed in the US. An additional issue is that the temperature, salinity, and pressure sensors on these floats must be more accurate than for standard Argo floats, since the variability in the abyssal ocean is likely to be considerably smaller than in the upper $2000 \mathrm{~m}$ of the water column. Prototypes for the $4000 \mathrm{~m}$ versions have been successfully deployed in the N. Atlantic and N. Pacific. A dedicated test cruise for deployment of $6000 \mathrm{~m}$ prototype floats and for calibration and validation of new ultra-accurate temperature/salinity/pressure sensors took place in the western S. Pacific in mid-2014 and successfully showed the promise of both the new deep floats and sensors. While the deep floats will surely be more costly than present Argo floats, it is hoped that by 2020 systematic sampling of the abyssal ocean will be implemented, with as much as 30\% of the Argo array comprised of these deep floats. High-quality sampling of the deep sea from dedicated hydrographic vessels will need to continue far into the future, however, even after the full complement of deep floats is in place; the shipboard surveys together with Argo will provide a more complete global sampling of the abyssal ocean, and the ship-based data will be necessary to monitor the quality of the Argo data in the abyss.

It is possible that a decade or two from now the science community will barely recognize the deployment strategies or the instruments being deployed by Argo or its successor programs at that time. For the next few years, the AST has suggested continuing with its long-term plan while also moving in new directions that are part evolution (deploying floats in new and special regions, and the addition of new sensors) and part revolution (designing and testing floats capable of operation in the abyss). The goals of all of this work are to sustain the present systematic observations of the global ocean and to further improve our assessment of the ocean's role in climate.

The development of Deep Argo appears to be an especially crucial step in the evolution of the program. The present array has done a credible job of providing estimates of the heat content change in the upper $2000 \mathrm{~m}$ of the world ocean over the past few decades, with the measured increases being significant but somewhat smaller 
the world ocean, beneath the present limits of Argo sampling, as a possible repository of the increased heating necessary to close the global heat budget. Assessing this question, and making progress in other new directions such as observing the oceanic carbon cycle from floats, helping to make improved forecasts of ENSO and IOD, and probing the depths of marginal seas, will likely challenge the abilities of future leaders of Argo to push the limits of evolution and revolution of the program in order to further increase our understanding of the circulation of the ocean and its role in climate.

In conclusion, it is important to remember that the prize we are aiming for is an understanding of how the ocean is changing both naturally and as a result of human activities. That said, Argo is indeed a major accomplishment but it does not stand alone. Recently five programs have been brought together in the JCOMMOPS (Joint Commission on Oceanography and Marine Meteorology Operations) office. This includes moored buoy activities such as the equatorial arrays and the individual moorings sponsored by the OceanSites program, also the XBT surveys and the repeat ship-board hydrographic surveys sponsored by the GO-SHIP program. Many of these supply data in real-time in parallel with the Argo program. With all of these programs now operating under a single umbrella the supply of data from the oceans is undergoing a profound transformation.

Author Contributions: The paper was written by SCR (60\%) and HJF(40\%), with editorial comments and suggestions provided by the remaining co-authors whohave all served as members of the Argo Steering Team and so have contributed significantly to the Argo program.

\section{Author Affiliations:}

Dept. of Oceanography, University of Washington, Seattle, WA 98195, U.S.A.

Steve Riser

Fisheries and Oceans Canada, Institute of Ocean Sciences, North Saanich, BC V8L 4B2 CANADA Howard Freeland

Scripps Institution of Oceanography, 9500 Gilman Dr.,\#0230, La Jolla, CA 92093-0230, USA

Dean Roemmich

Centre for Australian Weather and Climate Research, CSIRO, Hobart, Tasmania, 7004, Australia

Susan Wijffels and Ann Thresher

Servicio de Hidrografia Naval, A. Montes de Oca 2124, Buenos Aires, ARGENTINA

Ariel Troisi

JCOMMOPS, BP70, Plouzane, 29280 FRANCE

Mathieu Belbeoch

Denis Gilbert

Fisheries and Oceans Canada, Institut Maurice-Lamontagne, Mont-Joli, Quebec, G5H 3Z4 Canada 
The Second Institute of Oceanography, SOA, No.36 Baochubei Road, Hangzhou, Zhejiang, CHINA 310012 Jianping Xu

IFREMER \& MERCATOR OCEAN, 8-10 rue Hermes Parc Technologique du Canal, Ramonville St. Agne, FRANCE 31520

Pierre-Yves Le Traon

IFREMER, BP70, Plouzané, 29280 FRANCE

Guillaume Maze and Sylvie Pouliquen

Bundesamt fuer Seeschifffahrt und Hydrographie, bernhard-Nocht-str., 78, Hamburg, Germany 20359

Birgit Klein

Indian National Centre for Ocean Information Services, Hyderabad, Andhra Pradesh, 500090, India

M. Ravichandran

International Programmes, Marine Institute, Wilton Park House, Wilton Place, Dublin 2, Ireland

Fiona Grant

OGS, Borgo Grotta Gigante, 42/c, Sgonico, Trieste, ITALY 34010

Pierre-Marie Poulain

JAMSTEC and Tohoku University, Aramaki-Aza-Aoba 6-3, Aoba-Ku, Sendai, Miyagi, 980-8578 Japan

Toshio Suga

National Institute of Meteorological Research/KMA, 45 Gisangcheong-gil, Dongjak-gu, Seoul, KOREA, 156720

Byunghwan Lim

KNMI, P.O. Box 201, 3730 AE de Bilt, Netherlands

Andreas Sterl

National Institute of Water and Atmospheric Reseach, 301 Evans Bay Parade, Greta Point, Wellington, NZ, 6021

Philip Sutton

Institute of Marine Research, P.O. Box 1870 Nordnes, 5817 Bergen, Norway

Kjell-Arne Mork

Instituto Español de Oceanografía, Vía Espaldón, Dársena Pesquera, Parcela 8, 38180 Santa Cruz de Tenerife, España

Pedro Joaquín Vélez-Belchí

University of Cape Town, 7701 Rondebosch, South Africa

Isabelle Ansorge

National Oceanography Centre, Southampton, Empress Dock, Southampton, Hampshire, S014 3ZH UK

Brian King

Met Office, FitzRoy Rd, Exeter, Devon EX1 3PB UK

Jon Turton 
Author Information: All data used in this paper are freely available from the Argo Global Data Assembly 428 Center at http://www.coriolis.eu.org/Data-Products. The authors of this work have no competing financial 429 interests related to the material published here. Correspondence and requests for materials should be addressed 430 to HJF at howard.freeland@dfo-mpo.gc.ca. Reprints and permissions information is available at 431 http://www.nature.com/reprints.

432

433 Acknowledgments: Argo data were collected and made freely available by the International Argo Program and 434 the national programs that contribute to it. (http://www.argo.ucsd.edu, http://argo.jcommops.org). The Argo 435 Program is part of the Global Ocean Observing System.

436

437

438

439 
442 1. Argo Science Team. On the design and Implementation of Argo - An initial Plan for a global array of 443 Profiling Floats. International CLIVAR project Office ICPO Report No.21. GODAE Report No 5. Published by 444 the GODAE International Project office, c/o Bureau of Meteorology, Melbourne, Australia, 32pp (1998).

445 2. Intergovernmental Oceanographic Commission (IOC) Toward a global ocean observing system: the 446 approach to GOOS. IOC publication IOC-XVII/8, UNESCO, Paris (1993).

447 3. Boyer, T. et al. World Ocean Database 2009. S. Levitus, ed. NOAA Atlas NESDIS 66, U.S. Gov.

448 Printing Office, Wash., D.C., 216 pp (2009).

449 4. http://dx.doi.org/10.12770/ca035889-880d-463e-a523-10aabc3d6be3

450 5. Intergovernmental Panel on Climate Change (IPCC). Climate Change 2014: Synthesis Report. IPCC 451 Geneva, pp 151 (2014).

452 6. Intergovernmental Panel on Climate Change (IPCC). Climate Change 2007: Synthesis Report. IPCC 453 Geneva, 104 pp (2007).

454 7. Wong, A. \& Riser, S. Profiling float observations of the upper ocean under sea ice off the Wilkes Land coast 455 of Antarctica. Journal of Physical Oceanography, 41, 1102-1115 (2011).

456 8. Wong, A. \& Riser, S. Modified shelf water on the continental slope north of Mac Robertson Land, East 457 Antarctica. Geophysical Research Letters, 40, 6186-6190 (2013).

458 9. Wong, A., Johnson G., \& Owens, W.B. Delayed-mode calibration of autonomous CTD profiling float 459 salinity data by theta-S climatology. Journal of Atmospheric and Oceanic Technology, 20, 308-318 (2003).

460 10. Owens, W.B. \& Wong, A. An improved calibration method for the drift of the conductivity sensor on 461 autonomous CTD profiling floats by theta-S climatology, Deep-Sea Research Part I: Oceanographic Research 462 Papers, 56, 450-457 (2009).

463 11. Gaillard, F. et al. Quality Control of Large Argo Datasets. Journal of Atmospheric and Oceanic Technology, 464 26, 337-351(2009).

465 12. Levitus, S. Climatological Atlas of the World Ocean, NOAA Professional Paper 13, U.S. Gov. Printing 466 Office, Rockville, M.D., 190 pp (1982).

467 13. von Schuckmann, K., Gaillard, F., \& Le Traon, P-Y. Global hydrographic variability patterns during 2003468 2008. Journal of Geophysical Research-Oceans, 114, C09007, doi:10.1029/2008JC005237 (2009). 

and Oceanic Technology, 30, 759-788 (2013).

471 15. Ollitrault, M. \& De Verdiere, C. The ocean general circulation near $1000 \mathrm{~m}$ depth. Journal of Physical 472 Oceanography, 44, 384-409 (2014).

16. Gray, A. \& Riser, S. A global analysis of Sverdrup balance using absolute geostrophic velocities from Argo. Journal of Physical Oceanography, 44, 1213-1229 (2014).

17. Castelao, R. Mesoscale eddies in the South Atlantic Bight and the Gulf Stream recirculation region: vertical structure. Journal of Geophysical Research-Oceans, doi: 10.1002/2014JC009796 (2014).

18. Zhang, Z., Wang, W., \& Qiu, B. Oceanic mass transport by mesoscale eddies. Science, 345, 322-324 478 (2014).

19. Hennon, T., Riser, S., \& Alford, M. Observations of internal gravity waves from Argo floats. Journal of 480 Physical Oceanography, 44, 2370-2386 (2014).

20. Mercier, H. et al. Variability of the meridional overturning circulation at the Greenland--Portugal OVIDE section from 1993 to 2010. Progress in Oceanography, 132, 250-261 (2015).

21. Guinehut, S., Dhomps A., Larnicol, G., \& Le Traon, P-Y. High resolution 3-D temperature and salinity fields derived from in situ and satellite observations. Ocean Science, 68, 845-857 (2012).

22. Willis, J. K., and L.-L. Fu (2008), Combining altimeter and subsurface float data to estimate the timeaveraged circulation in the upper ocean, J. Geophys. Res., 113, C12017, doi:10.1029/2007JC004690. 1960-2010 from the GFDL ensemble coupled data assimilation. Climate Dynamics, 40, 775-803 (2013). expedition and the Argo Programme. Nature Climate Change, 2, 425-428 (2012). Geophysical Research Letters, 40, 2252-2258 (2013). height in the global ocean from the Argo Program. Progress in Oceanography, 82, 81-100 (2009). 
497

498

499

500

501

502

503

504

505

506

507

508

509

510

511

512

513

514

515

516

517

518

519

520

521

522

523

524

525

29. Roemmich, D. et al. Unabated Planetary Warming and its Anatomy since 2006. Nature Climate Change, 5, 240-245 (2015).

30. Durack, P. \& Wijffels, S. Fifty-year trends in global ocean salinities and their relationship to broad-scale warming. Journal of Climate, 23, 4342-4362 (2010).

31. Hosoda, S., Suga, T., Shikama, N., and Mizuno, K. Global surface layer salinity change detected by Argo and its implication for hydrological cycle intensification. Journal of Oceanography, 65, 579-586 (2009).

32. Durack, P., Wijffels, S. \& Matear, R. Ocean salinities reveal strong global water cycle intensification during 1950-2000. Science, 336, 455-458 (2012).

33. Manabe, S. \& Stouffer, R. Multiple-century response of a coupled ocean-atmosphere model to an increase of atmospheric carbon dioxide. Journal of Climate, 7, 5-23 (1994).

34. Yashayaev, I. \& and Loder, J. Enhanced production of Labrador Sea Water in 2008. Geophysical Research Letters, 36, doi:10.1029/2008GL036162 (2009).

35. Kieke, D., Yashayaev, I. Studies of Labrador Sea Water formation and variability in the subpolar North Atlantic in the light of international partnership and collaboration. Prog. Oceanogr. (2015), doi:10.1016/j.pocean.2014.12.010

36. Ren, L. \& Riser, S. Seasonal salt budget in the northeast Pacific Ocean. Journal of Geophysical Research, 114, doi:10.1029/2009JC005307 (2009).

37. Ren, L. \& Riser, S. Observations of decadal-scale salinity changes in the thermocline of the North Pacific Ocean. Deep-Sea Research II, 57, 1161-1170 (2010).

38. Freeland, H. Evidence of change in the winter mixed layer in the Northeast Pacific Ocean: a problem revisited. Atmosphere-Ocean, 51, 126-133 (2013).

39. Hansen, J., Lacis, A., \& Rind, D. Climate trends due to increasing greenhouse gases. In: Proceedings of the Third Symposium on Coastal and Ocean Management, ASCE/San Diego, California, June 1-4, 1983, 2796-2810 (1984).

40. Palmer, M., McNeall, D., \& Dunstone, N. Importance of the deep ocean for estimating decadal changes in Earth’s radiation balance. Geophysical Research Letters, 38, doi:10.1029/2011GL047835 (2011).

41. Rhein, M. et al. Observations: Ocean. In: Climate Change 2013: The Physical Science Basis. Contribution of Working Group I to the Fifth Assessment Report of the Intergovernmental Panel on Climate Change. Cambridge University Press, Cambridge, United Kingdom and New York, NY, USA (2013). 
526 42. Sutton, P. \& Roemmich, D. Decadal steric and sea surface height changes in the Southern Hemisphere.

527 Geophyical Research Letters, 38, doi: 10.1029/2011GL046802 (2011).

528 43. Kosaka, Y. \& and Xie, S-P. Recent global-warming hiatus tied to equatorial Pacific surface cooling. Nature, 501, 529 403-407 (2013).

530 45. Durack, P., Gleckler, P., Landerer, F., \& Taylor, K. Quantifying underestimates of long-term upper ocean 531 warming. Nature Climate Change, doi:10.1038/NCLIMATE2389 (2014).

532 46. Freeland, H. et al. Argo-a decade of progress. In: Proceedings of OceanObs'09: Sustained Ocean 533 Observations and Information for Society (V2), Venice, Italy, 21-25 September 2009: ESA Publication WPP534306 10.5270/OceanObs09.cwp.32 (2010).

535 47. Kwon, Y-O. et al. Role of Gulf Stream, Kuroshio-Oyashio, and their extensions in large-scale atmosphere536 ocean interaction : a review. Journal of Climate, 23, 3249-3281 (2010).

537 48. Saji, N., Goswami, B., Vinayachandran, P., \& Yamagata, T. A dipole mode in the tropical Indian Ocean. 538 Nature, 401, 360-363 (1999).

539 49. Klatt, O., Boebel, O., \& Fahrbach, E. A profiling float's sense of ice. Journal of Atmospheric and Oceanic 540 Technology, 24, 1301-1308 (2007).

541 50. Johnson, K. et al. Observing biogeochemical cycles at global scales with profiling floats and gliders: 542 prospects for a global array. Oceanography, 22, 216-225 (2009).

543 51. Brasseur, P. et al. Integrating biogeochemistry and ecology into ocean data assimilation systems. 544 Oceanography, 22, 206-215 (2009).

545 52. International Ocean Colour Coordinating Group (IOCCG). Bio-Optical Sensors on Argo Floats. Reports of 546 the International Ocean-Colour Coordinating Group, 11, H. Claustre, ed. IOCCG, Dartmouth, Canada (2011).

547 53. Frolicher, T. et al. Dominance of the Southern Ocean in anthropogenic carbon and heat uptake in CMIP5 548 models. Journal of Climate, 28 862-886 (2015).

549 54. Morrison, A., Frolicher, T. and Sarmiento, J. Upwelling in the Southern Ocean. Physics Today, 68, 27-29 550 (2015).

551 55. Fukasawa, M., et al. Bottom water warming in the North Pacific Ocean. Nature, 427, 825-827 (2004).

552 56. Johnson, G., Purkey, S., \& Bullister, J. Warming and freshening in the abyssal southeastern Indian Ocean. 553 Journal of Climate, 21, 5351-5363 (2008). 
554 57. Purkey, S. \& Johnson, G. Warming of global abyssal and deep Southern Ocean waters between the 1990s 555 and 2000s: contributions to global heat and sea level rise budgets. Journal of Climate, 23, 6336-6353 (2010).

556 58. Purkey, S., \& Johnson, G. Antarctic Bottom Water warming and freshening: contributions to sea level rise, 557 ocean freshwater budgets, and global heat gain. Journal of Climate, 26, 6105-6122 (2013).

558

559

560

561

562

563

564

565

566

567

568

569

570

571

572

573

574

575

576

577

578

579 


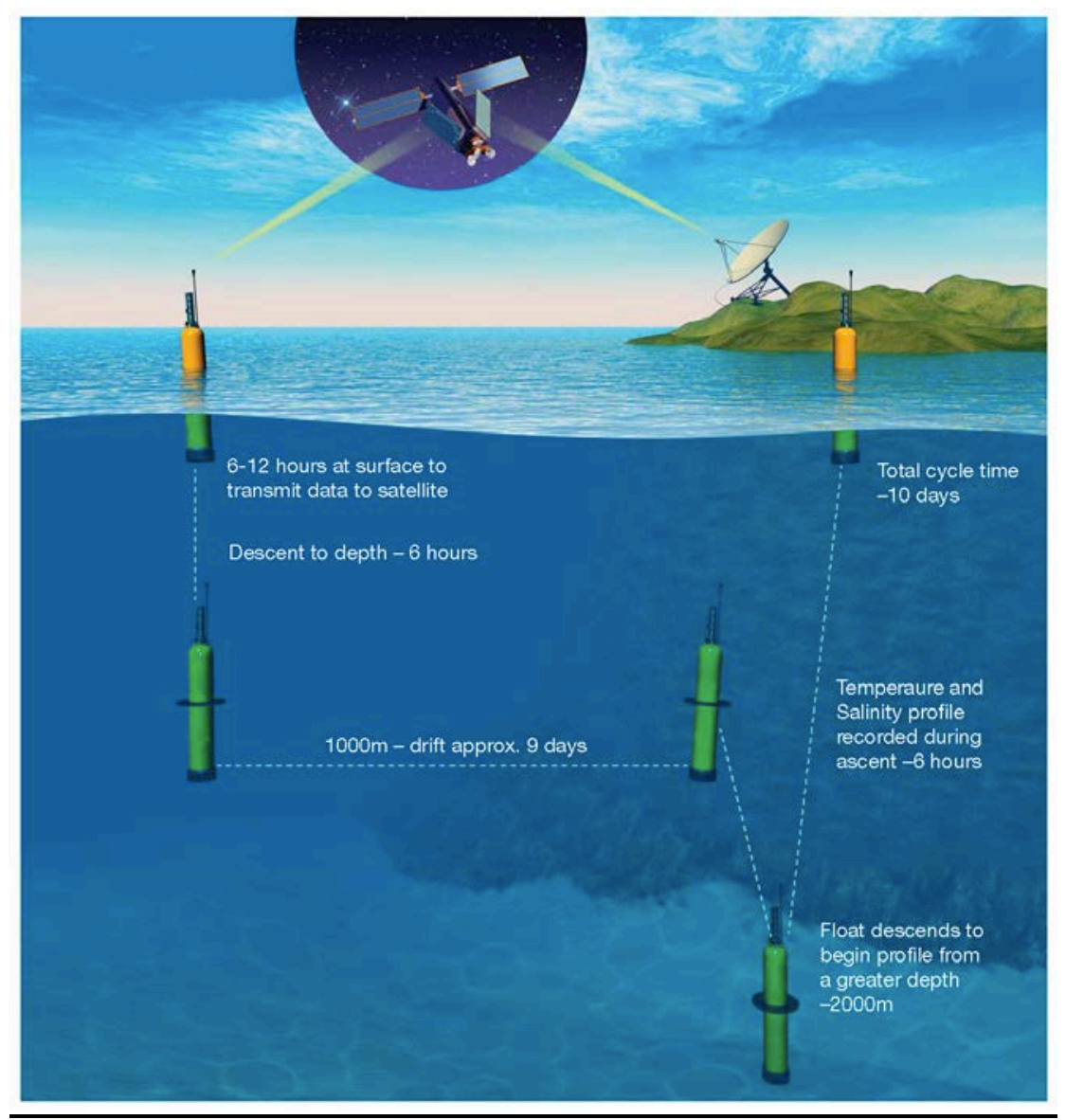

582 Figure 1. In the cycle typical of an Argo float, a float starts at the surface and dives to a depth of 1000 meters 583 (the parking depth) where it rests for 9 to 10 days. After 9 days at rest it dives to a depth of $2000 \mathrm{~m}$, turns on its 584 sampling equipment and measures ocean properties as it rises to the surface where it rests for sufficient time to 585 transmit the data collected to Argos or Iridium satellite systems. It then returns to the parking depth to start 586 another cycle, the typical duration of a complete cycle is 10 days. 


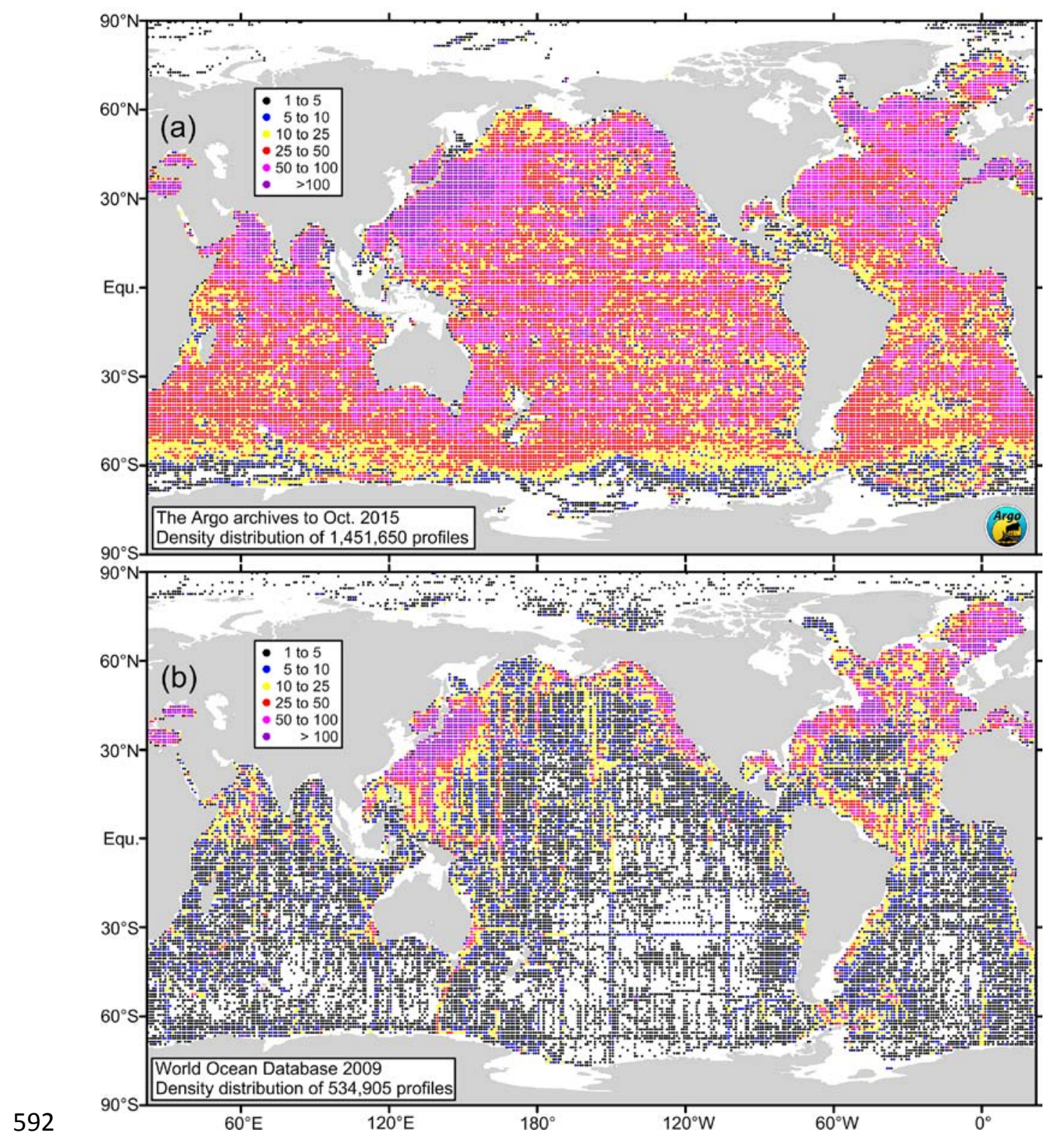

593 Figure 2. The sampling density of profiles reported by Argo floats ${ }^{4}$ (upper panel; 1.5 million collected between 5941999 to Oct. 2015), and (lower panel) by the most complete assembly of all previous historical efforts (0.5 595 million largely shipboard observations collected over the past 100 years from the World Ocean Data Base $5962009^{3}$ ). This sampling density is computed as the total number of samples in each $1^{\circ}$ latitude $\times 1^{\circ}$ longitude 597 square and is color coded according to the legend on each panel. The analysis only includes profiles that sample 598 both temperature and salinity to a depth 

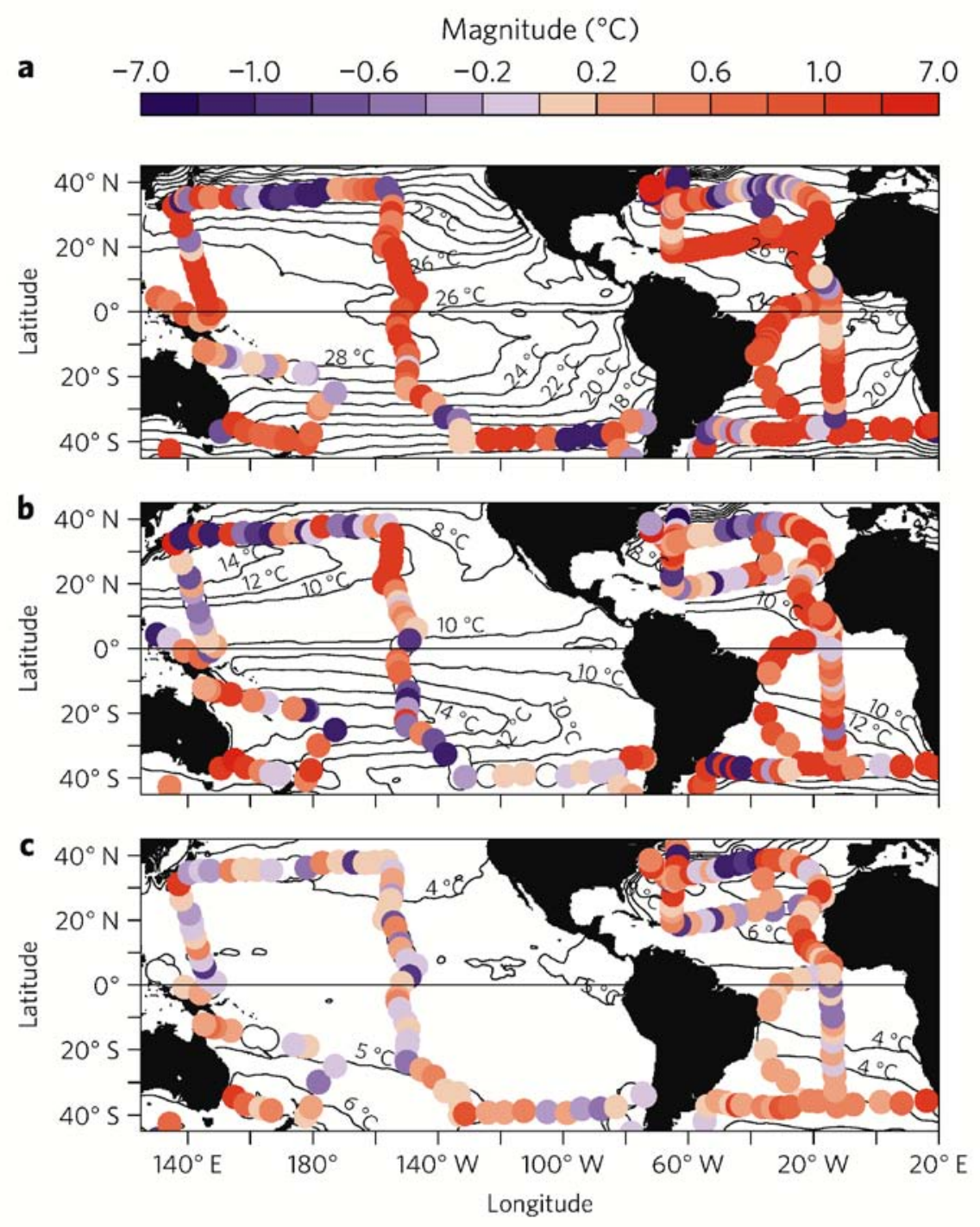

of $1000 \mathrm{~m}$ or deeper.

602

603 Figure 3: Contours of the mean temperature over the period 2004-2010 in the global ocean ${ }^{26}$ at $(a)$ the sea 604 surface, $(b)$ a depth of $366 \mathrm{~m}$, and $(c)$ a depth of $914 \mathrm{~m}$, using Argo data; the dots denote the Argo minus 605 Challenger temperature difference, according to the color scale. Reprinted from (23). 


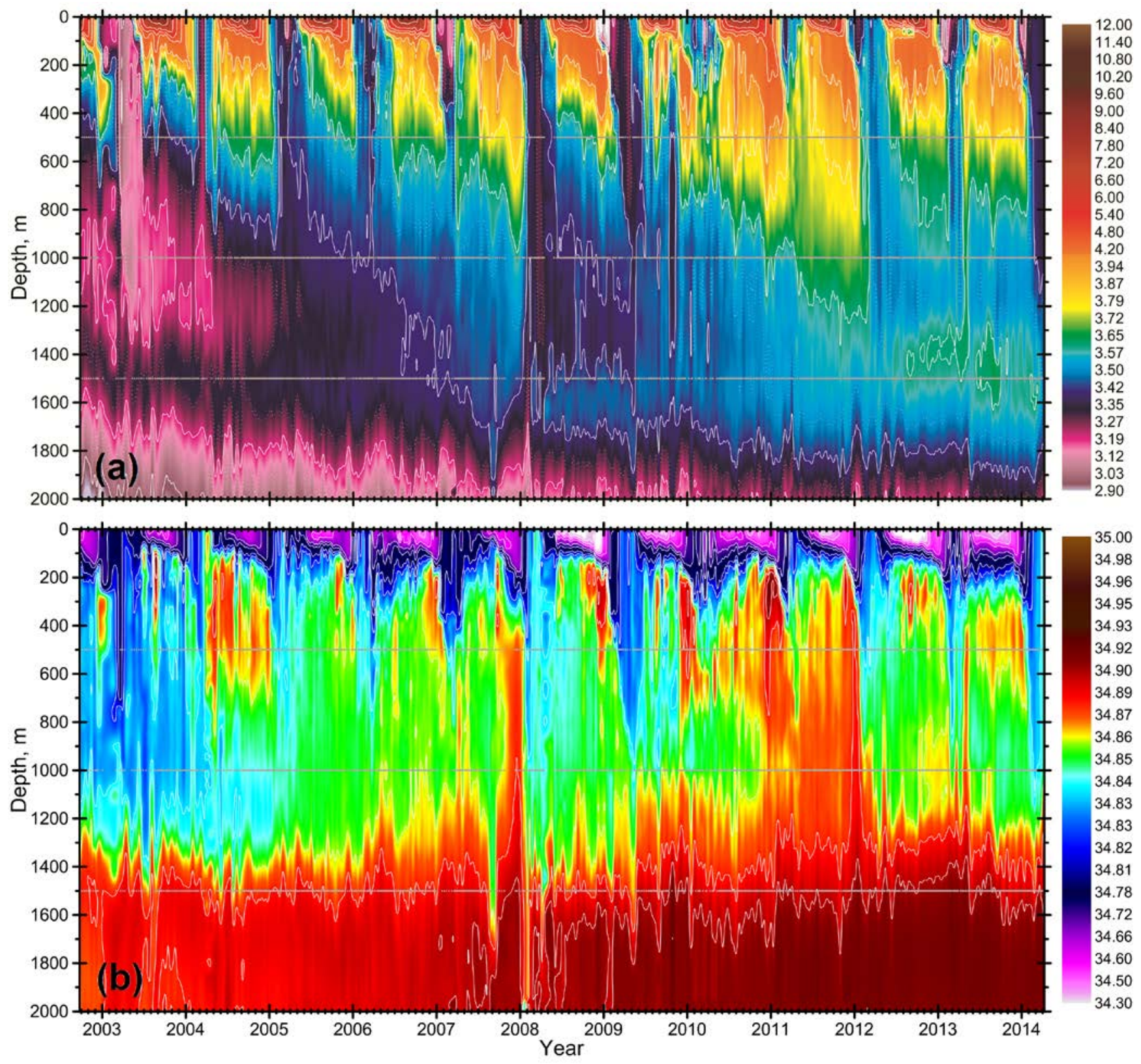

609

610 Figure 4. The seasonal to interannual evolution of potential temperature (a) and salinity (b) in the upper $2000 \mathrm{~m}$

611 of the Labrador Sea during the period 2002-2014, compiled from Argo observations and recomputed from data

612 forming the original figure published by Kieke and Yashayaev ${ }^{33}$. 


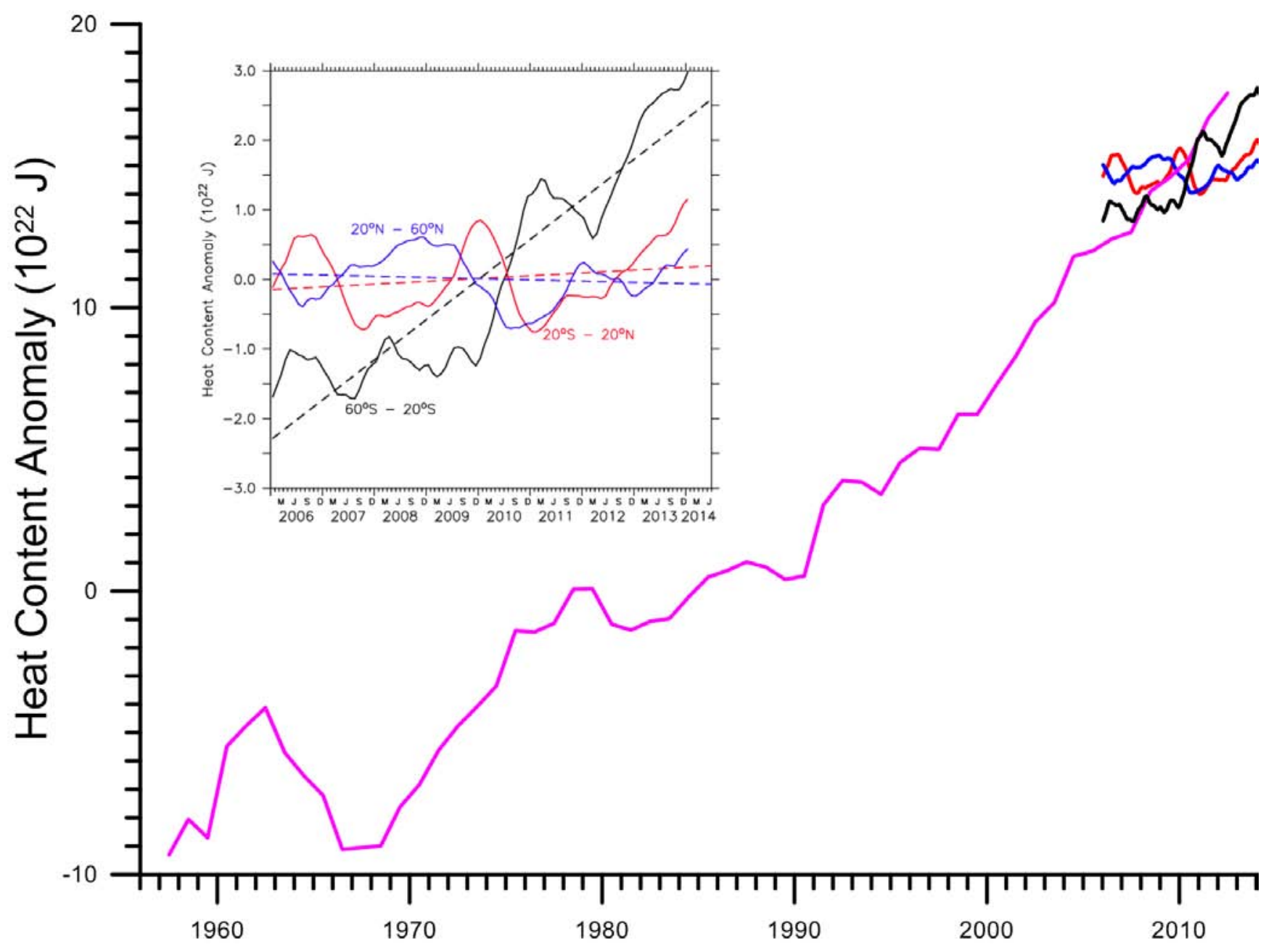

616

Figure 5: Estimates of the global heat content anomaly $\mathrm{y}^{27}$, for latitude ranges $60^{\circ} \mathrm{S}-20^{\circ} \mathrm{S}$ (black), $20^{\circ} \mathrm{S}-20^{\circ} \mathrm{N}$

618 (red), and $20^{\circ} \mathrm{N}-60^{\circ} \mathrm{N}$ (blue), computed as 12-month running mean values and shown as an inset. Smoothed 619 trends are shown as the dashed lines on the figure in the same colors; the colored numbers in parentheses refer to

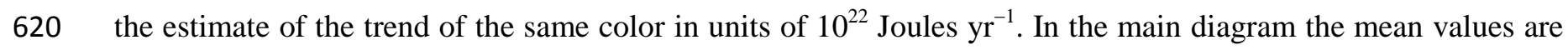
621 changed so that they overlay the $0-2000 \mathrm{~m}$ heat content computed by Levitus et al. ${ }^{44}$ 